\title{
Factors Contributing to Diagnostic Discordance Between Store-and-Forward Teledermatology Consultations and In-Person Visits: Case Series
}

Michelle S Lee ${ }^{1}$, BA; Robert Stavert ${ }^{2}$, MD, MBA

${ }^{1}$ Harvard Medical School, Boston, MA, United States
${ }^{2}$ Department of Dermatology, Cambridge Health Alliance, Somerville, MA, United States

Corresponding Author:

Michelle S Lee, BA

Harvard Medical School

25 Shattuck Street

Boston, MA, 02115

United States

Phone: 14127217765

Email: michelle lee3@hms.harvard.edu

\section{Abstract}

Background: Use of asynchronous store-and-forward (SAF) teledermatology can improve access to timely and cost-effective dermatologic care and has increased during the COVID-19 pandemic. Previous research has found high diagnostic concordance rates between SAF teledermatology and face-to-face clinical diagnosis, but to our knowledge, none have used specific cases to illustrate factors contributing to diagnostic discordance.

Objective: To identify and illustrate characteristics that may have contributed to diagnostic discordance between store-and-forward teledermatology and in-person clinical diagnosis in a series of patients.

Methods: We identified 7 cases of diagnostic discordance between teledermatology and in-person visits where the favored diagnosis of the in-person dermatologist was not included in the differential diagnosis formulated by the teledermatologist. Cases were identified from a previously published retrospective chart review of 340 SAF teledermatology consultations, which was previously performed at an academic community health care system in the greater Boston area, Massachusetts, from January 1, 2014, through December 31, 2017. Of 99 patients who completed an in-person dermatology appointment after their teledermatology consultation, 7 had diagnostic disagreement between the teledermatologist and in-person dermatologist where the diagnosis in the in-person consultation was not included in the differential diagnosis in the original teledermatology consult. These 7 cases were examined by 2 author reviewers to identify factors that may have contributed to diagnostic discordance.

Results: Factors contributing to diagnostic discordance between SAF teledermatology consultations and in-person visits included poor image quality, inadequate history or diagnostic workup, inability to evaluate textural characteristics, diagnostic uncertainty due to atypical presentations, and evolution in appearance of skin conditions over time.

Conclusions: We identified multiple factors that contributed to diagnostic discordance. Recognition and mitigation of these factors, when possible, may help to improve diagnostic accuracy and reduce the likelihood of misdiagnosis. Continuing education of referring providers and implementation of standardized guidelines for referrals may also be helpful in reducing the risk of misdiagnosis due to inherent limitations of teledermatology services.

(JMIR Dermatol 2021;4(1):e24820) doi: $10.2196 / 24820$

\section{KEYWORDS}

teledermatology; eHealth; dermatology; telemedicine; diagnosis

\section{Introduction}

Store-and-forward (SAF) teledermatology systems utilize asynchronous evaluation of clinical images and information to provide diagnostic and management guidance directly to patients or other health care providers. In contrast to real-time telemedicine such as video encounters, SAF encounters involve collecting clinical information from a referring provider to be 
sent electronically to another site or provider, often a specialist, for review at a later time. SAF teledermatology platforms can increase access to dermatologic care, provide financial savings for patients and health systems, and provide a comparable quality of care to in-person evaluation for numerous dermatologic conditions [1-8]. Utilization of both synchronous video and asynchronous $\mathrm{SAF}$ telemedicine has increased significantly during the 2020 COVID-19 pandemic [9,10]. SAF teledermatology may play a particularly vital role in the provision of safe and efficient dermatologic care as it requires less resources and coordination to implement compared to live interactive teledermatology [11].

Evaluation of diagnostic concordance for patients who receive both a teledermatology and in-person consultation is one method of assessing the diagnostic quality of SAF teledermatology consultations. Complete diagnostic concordance occurs when the first diagnosis matches between the in-person dermatologist and teledermatologist [12-17]. Previous research has found $79 \%-94 \%$ concordance rates between teledermatology and face-to-face clinical diagnosis, with some variation based on factors including skin condition and whether or not dermatoscopy is utilized [12-17]. High rates of diagnostic concordance help to ensure that the diagnoses patients receive from SAF teledermatology platforms are comparable to those that patients would receive during an in-person encounter.

Although previously published work has examined rates and patterns of discordance [12-17], to our knowledge, none have previously used cases to identify and illustrate specific characteristics that may contribute to diagnostic discordance. We analyzed a series of 7 cases of diagnostic discordance, identifying contributing factors in hopes of identifying opportunities to improve teledermatology systems and mitigate potential risks that can occur from misdiagnosis.

\section{Methods}

Previously, a retrospective chart review of 340 SAF teledermatology consultations performed at our institution from January 1, 2014, through December 31, 2017, was conducted [18]. All SAF teledermatology cases were ordered alphabetically by patient's last name, and the first 340 cases were reviewed. Among these 340 teledermatology cases, there were 99 patients who also completed an in-person dermatology visit, and further chart review was performed to determine the level of management concordance between teledermatologist and in-person dermatologist, defined by five categories: (1) fully concordant, (2) partially concordant, (3) discordant, (4) unable to assess because treatment was not specified by the referring provider, and (5) treatment not specified by teledermatology provider and an in-person appointment is requested for further evaluation. The definition of diagnostic discordance for this study was based on previous literature, which has defined diagnostic concordance as complete agreement (where the first diagnosis matched between in-person dermatologist and teledermatologist), partial agreement (where diagnoses overlapped between in-person dermatologist and teledermatologist), and discordant (where diagnoses did not match between teledermatologist and in-person dermatologist) [18-20]. Analysis of the 99 patients with both teledermatology and in-person visits found that diagnoses in $76(77 \%)$ encounters were fully concordant, 16 (16\%) were partially concordant, and $7(7 \%)$ were fully discordant. We further evaluated these 7 diagnostically discordant cases to identify factors contributing to diagnostic discordance. Both authors (MSL and RS) performed retrospective chart review of the cases and discussed causes of the diagnostic discordance to come to a consensus.

Images from the teledermatology consult were submitted by the referring provider and taken using the Epic Haiku mobile app (Epic Systems Corporation). The teledermatologist was different than the in-person dermatologist in all but the second case reviewed. This project was exempt from full review by our Institutional Review Board.

\section{Results}

\section{Overview}

A summary of the cases, teledermatology and in-person differential diagnoses, in-person diagnosis, and factors contributing to diagnostic discordance is provided in Table 1. 
Table 1. Summary of cases and factors contributing to diagnostic discordance.

\begin{tabular}{|c|c|c|c|c|c|c|}
\hline Case & $\begin{array}{l}\text { Age }(\mathrm{yrs}) \\
\text { and gender }\end{array}$ & $\begin{array}{l}\text { Telederm } \\
\text { a differential } \\
\text { diagnosis }\end{array}$ & $\begin{array}{l}\text { Treatment after } \\
\text { telederm visit }\end{array}$ & $\begin{array}{l}\text { In-person differential } \\
\text { diagnosis }\end{array}$ & $\begin{array}{l}\text { In-person diagnosis } \\
\text { (diagnostic test) }\end{array}$ & $\begin{array}{l}\text { Contributing factors to diagnostic } \\
\text { uncertainty }\end{array}$ \\
\hline 1 & 31 , male & $\begin{array}{l}\text { Superficial morphea, } \\
\text { superficial dermato- } \\
\text { phyte infection, pityri- } \\
\text { asis rotunda, psoriasis, } \\
\text { parapsoriasis, CTCL } \\
\text { Hansen }\end{array}$ & None & $\begin{array}{l}\text { Confluent and reticulat- } \\
\text { ed papillomatosis of } \\
\text { Gougerot and Carteaud, } \\
\text { morphea, tinea corporis, } \\
\text { and discoid erythrasma }\end{array}$ & $\begin{array}{l}\text { Eczematous dermati- } \\
\text { tis (punch biopsy) }\end{array}$ & $\begin{array}{l}\text { Image quality compromised by } \\
\text { patient positioning and lighting } \\
\text { leading to shine artifact; unusual } \\
\text { morphology, presentation; lack of } \\
\text { historical details provided }\end{array}$ \\
\hline 2 & 60 , male & $\begin{array}{l}\text { Sarcoid, mycobacteri- } \\
\text { al, hypersensitivity, } \\
\text { lichenoid reaction, } \\
\text { pseudolymphoma, } \\
\text { arthropod bite, folli- } \\
\text { culitis }\end{array}$ & $\begin{array}{l}\text { Betamethasone } \\
\text { dipropionate } \\
0.05 \% \text { cream twice } \\
\text { a day }\end{array}$ & $\begin{array}{l}\text { Tinea corporis, sarcoid, } \\
\text { annular lichen planus }\end{array}$ & $\begin{array}{l}\text { Tinea corporis } \\
\left(\mathrm{KOH} \text { prep }{ }^{\mathrm{c}} \text { con- }\right. \\
\text { firmed) }\end{array}$ & $\begin{array}{l}\text { Image quality compromised by } \\
\text { limited view of anatomic area; } \\
\text { evolution of rash from time of } \\
\text { telederm to time of in-person visit } \\
\text { from papular to characteristic an- } \\
\text { nular with scale }\end{array}$ \\
\hline 4 & 63 , male & $\begin{array}{l}\text { Actinic keratoses, ex- } \\
\text { coriated papulopustu- } \\
\text { lar rosacea, squamous } \\
\text { cell carcinoma }\end{array}$ & None prescribed & $\begin{array}{l}\text { Telangiectasias due to } \\
\text { sun damage }\end{array}$ & $\begin{array}{l}\text { Nonspecific telang- } \\
\text { iectasias due to sun } \\
\text { damage (clinical di- } \\
\text { agnosis) }\end{array}$ & $\begin{array}{l}\text { Inability to palpate lesion to deter- } \\
\text { mine textural characteristics; im- } \\
\text { age artifact showing overlying } \\
\text { scale; no dermatoscopic images } \\
\text { taken during initial consultation }\end{array}$ \\
\hline 5 & 69, male & $\begin{array}{l}\mathrm{HSV}^{\mathrm{e}} \text {, erythema mul- } \\
\text { tiforme, contact der- } \\
\text { matitis, or pemphigus } \\
\text { vulgaris, and paraneo- } \\
\text { plastic pemphigus }\end{array}$ & None prescribed & $\begin{array}{l}\text { Allergic contact dermati- } \\
\text { tis vs actinic cheilitis }\end{array}$ & $\begin{array}{l}\text { Lichenoid dermatitis } \\
\text { (biopsy) }\end{array}$ & $\begin{array}{l}\text { HSV/VZV viral culture would } \\
\text { have been helpful when evaluating } \\
\text { vesicles on mucosal surfaces; diag- } \\
\text { nostically challenging case; lack } \\
\text { of historical details provided }\end{array}$ \\
\hline 6 & 41 , male & HSV, LGV ${ }^{\mathrm{f}}$ & None prescribed & Condyloma acuminata & $\begin{array}{l}\text { Epidermal inclusion } \\
\text { cyst (biopsy) }\end{array}$ & $\begin{array}{l}\text { Nonclassic presentation resulting } \\
\text { in diagnostic uncertainty; viral and } \\
\text { bacterial swab cultures would be } \\
\text { helpful for initial consult; difficul- } \\
\text { ty in distinguishing between vesi- } \\
\text { cles, pustules, cysts via telederm }\end{array}$ \\
\hline 7 & 65 , male & Unable to determine & None prescribed & $\begin{array}{l}\text { Irritated seborrheic ker- } \\
\text { atosis vs melanoma }\end{array}$ & $\begin{array}{l}\mathrm{BCC}^{\mathrm{g}} \text { (shave biop- } \\
\text { sy) }\end{array}$ & $\begin{array}{l}\text { Dermatoscopic images were out } \\
\text { of focus, and nondermatoscopic } \\
\text { images were not included }\end{array}$ \\
\hline
\end{tabular}

\footnotetext{
a Telederm: teledermatology.

${ }^{\mathrm{b}} \mathrm{CTCL}$ : cutaneous T-cell lymphoma.

${ }^{\mathrm{c}} \mathrm{KOH}$ prep: potassium hydroxide preparation.

${ }^{\mathrm{d}}$ VZV: varicella zoster virus.

${ }^{\mathrm{e}} \mathrm{HSV}$ : herpes simplex virus.

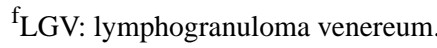

${ }^{\text {BCC: basal cell carcinoma. }}$
}

\section{Case 1}

A 31-year-old male presented to his primary care provider with a several-year history of well-circumscribed, hyperpigmented, nonpruritic, thin, scaly plaques with skin tightening on his back, trunk, and chest, as well as associated gynecomastia. The patient had tried applying moisturizing lotion without relief. Teledermatology consultation resulted in a broad differential diagnosis including superficial morphea, superficial dermatophyte infection, pityriasis rotunda, psoriasis, parapsoriasis, cutaneous T-cell lymphoma, and Hansen disease.
The submitted images showed several sharply demarcated hyperpigmented thin plaques with overlying xerotic scale on the back as well as well-circumscribed tan thin plaques with overlying scale on the collar distribution of the neck and the upper chest (Figures 1 and 2). The teledermatologist noted that the image quality was limited by patient positioning and lighting, leading to shine artifact, and noted that further history about potential exposures and travel history would have been helpful, particularly to rule out Hansen disease. Due to the broad differential and no leading diagnosis, he was referred for an in-person consultation. His in-person exam revealed 
well-demarcated geographic hyperpigmented atrophic and wrinkly patches on the back (Figure 3) and the anterior bilateral shoulders, left flank, and upper arms, as well as gynecomastia. The differential diagnosis included confluent and reticulated papillomatosis of Gougerot-Carteaud, morphea, tinea corporis, and discoid erythrasma. A punch biopsy was performed, which revealed findings most consistent with an eczematous dermatitis. The patient was treated with triamcinolone $0.1 \%$ cream and did not return for scheduled follow-up appointments.

Figure 1. Case 1. Submitted teledermatology image showing patient's back with hyperkeratotic plaque and xerotic scale. Image quality compromised by patient positioning and lighting leading to shine artifact.

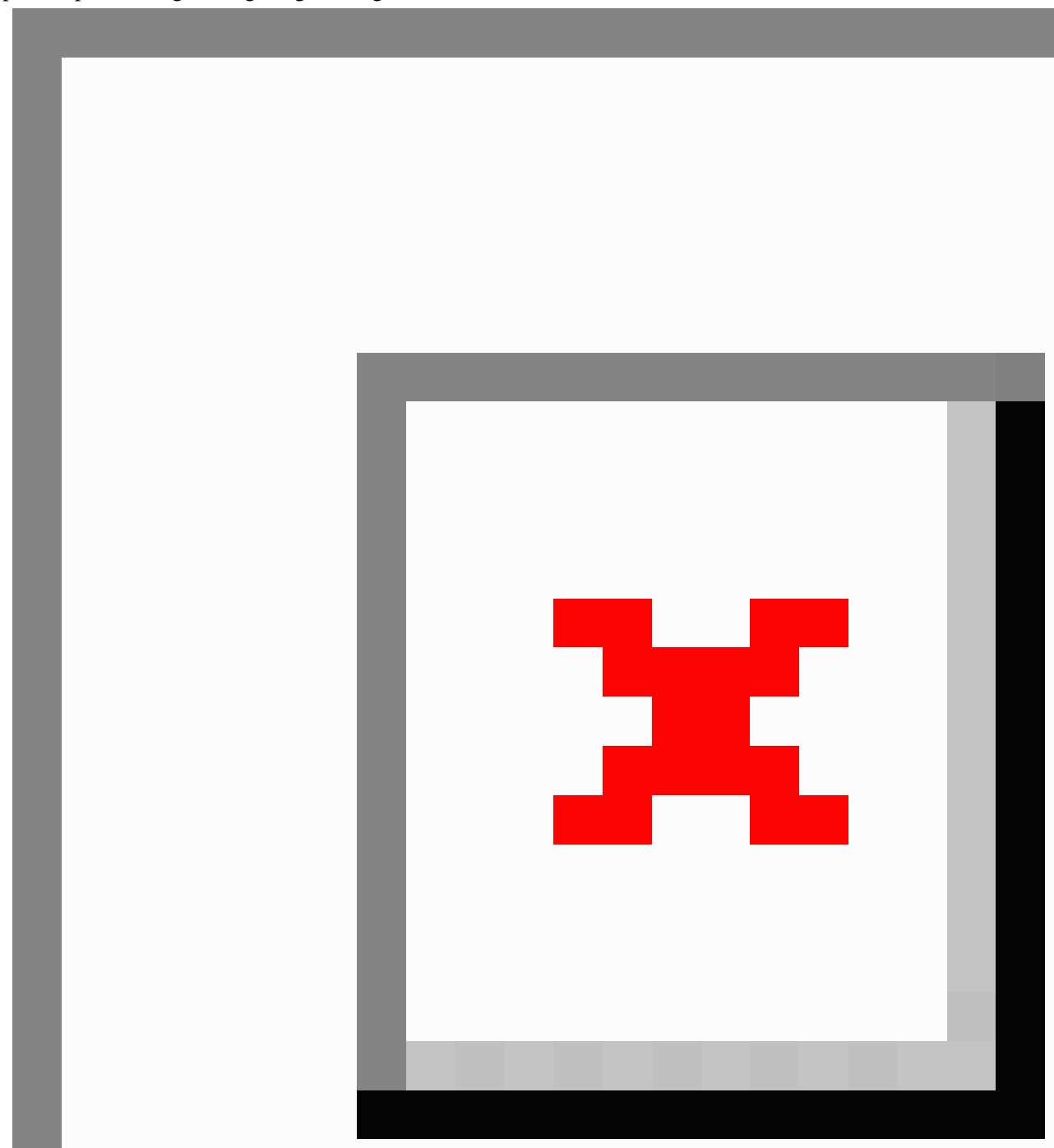


Figure 2. Case 1. Submitted teledermatology image showing patient's neck and clavicular region with hyperkeratotic plaque and xerotic scale. Image quality compromised by patient positioning and lighting leading to shine artifact.

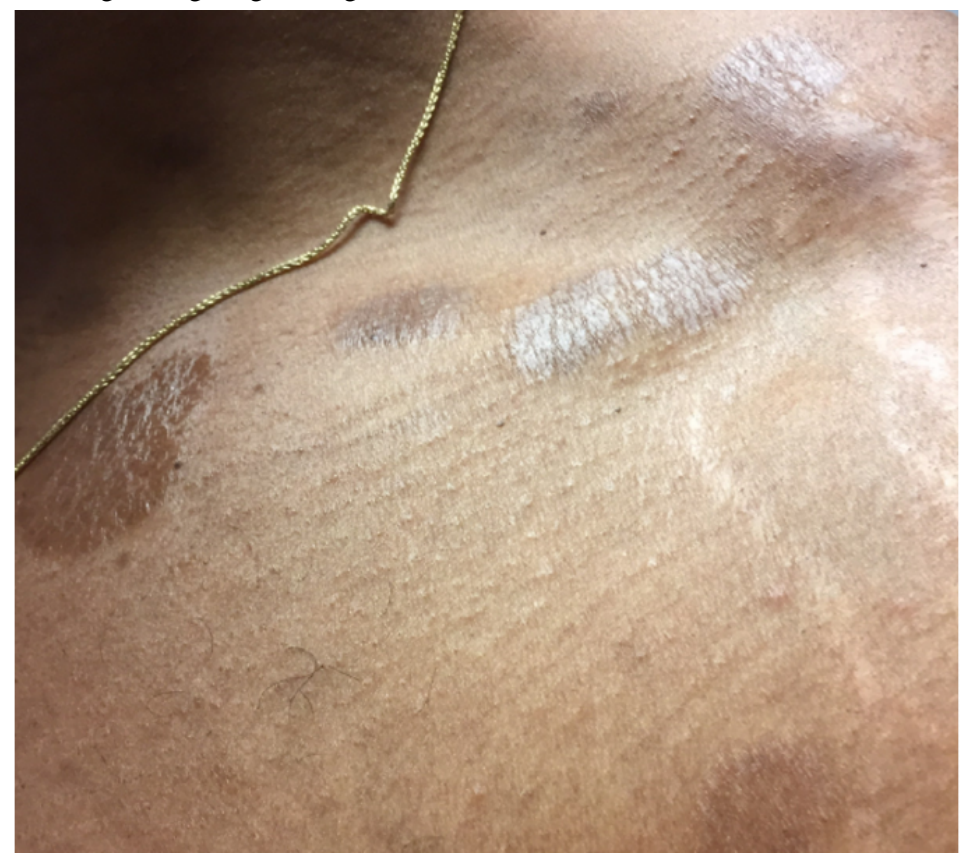

Figure 3. Case 1. Image for in-person visit showing well-demarcated, geographic, hyperpigmented, atrophic, and wrinkly patches on the back.

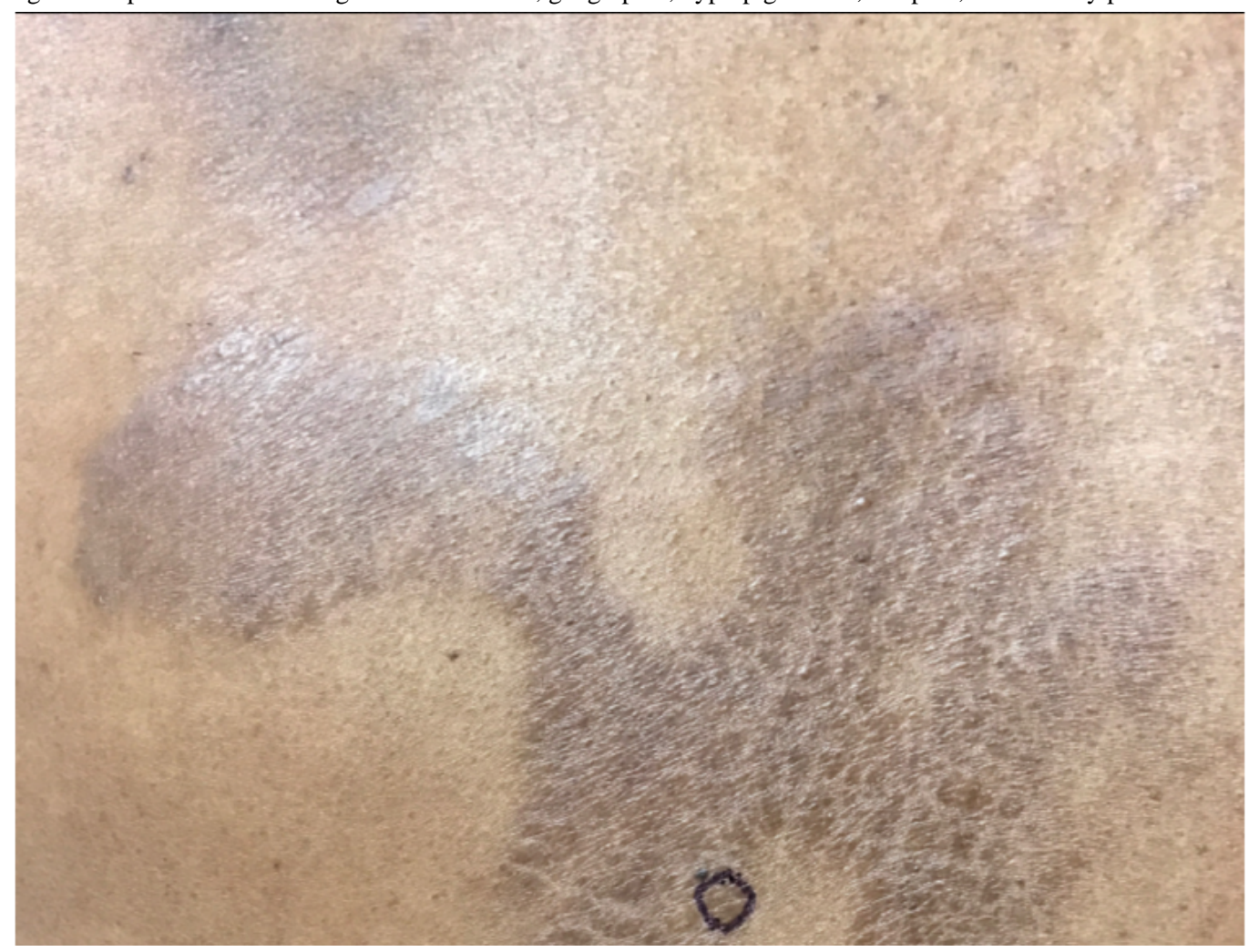

\section{Case 2}

A 60-year-old man with 3 weeks of pruritic pink papules on the left forearm next to tattooed skin was referred to teledermatology. Submitted photos showed a 1-2 cm light pink patch containing three discrete 4-6 mm pink papules, and the differential diagnosis included sarcoidosis, atypical mycobacterial infection, hypersensitivity reaction, lichenoid reaction, and pseudolymphoma, as well as arthropod assault and folliculitis. The teledermatologist noted that image quality was compromised by the limited anatomic view provided (Figure 4). The patient was prescribed betamethasone dipropionate $0.05 \%$ cream twice daily for 2 weeks. In the office 3 weeks later, he was noted to have a pink-red annular plaque with overlying scale (Figure 5) that was suspicious for tinea corporis, which was confirmed with a potassium hydroxide preparation (KOH prep) showing hyphae. The patient was treated with topical ketoconazole $1 \%$ cream, and his rash resolved without recurrence. 
Figure 4. Case 2. Submitted teledermatology image showing left forearm with $1-2 \mathrm{~cm}$ light pink patch containing three discrete 4-6 mm pink papules. Image quality compromised by limited anatomic view.

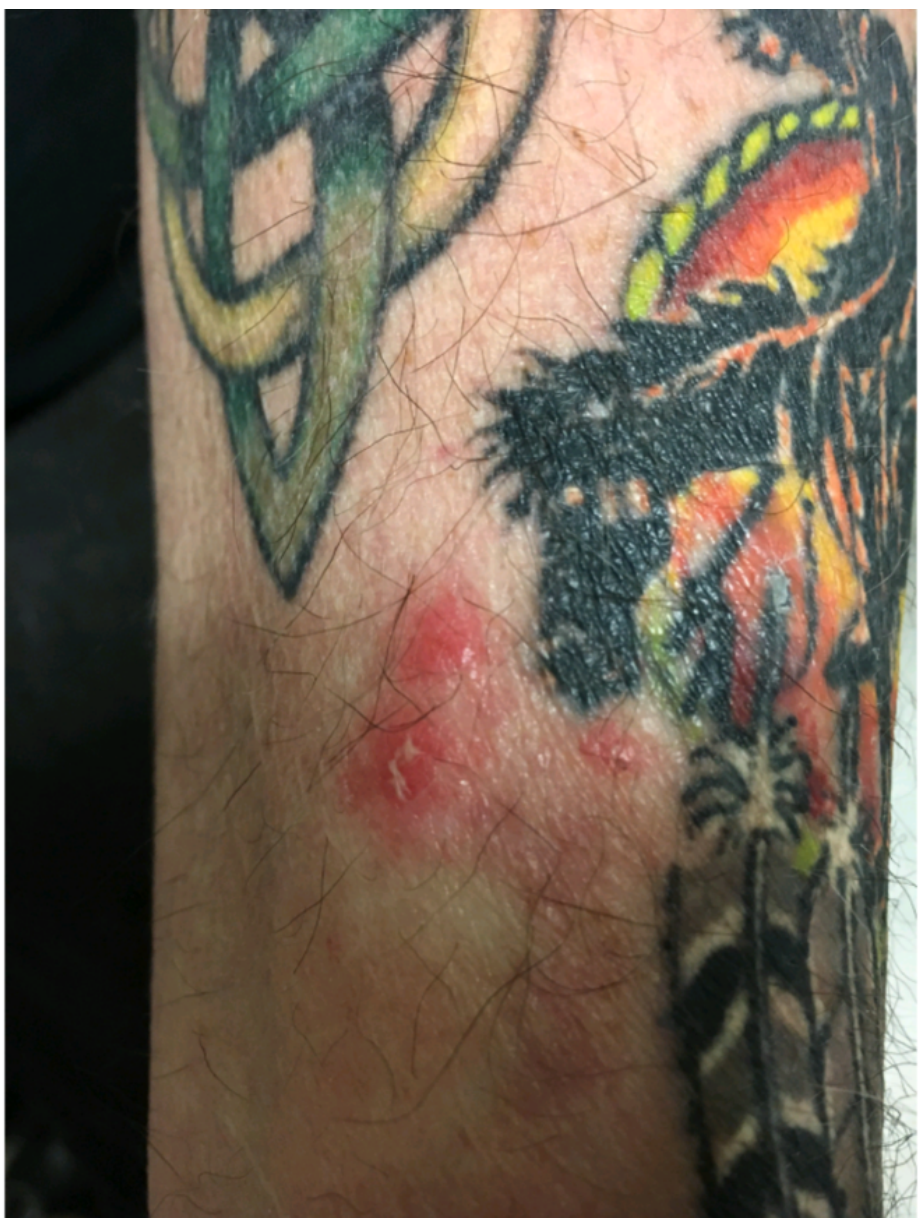

Figure 5. Case 2. In-office photo obtained from same patient, demonstrating left forearm with pink-red annular plaque with scale (tinea corporis).

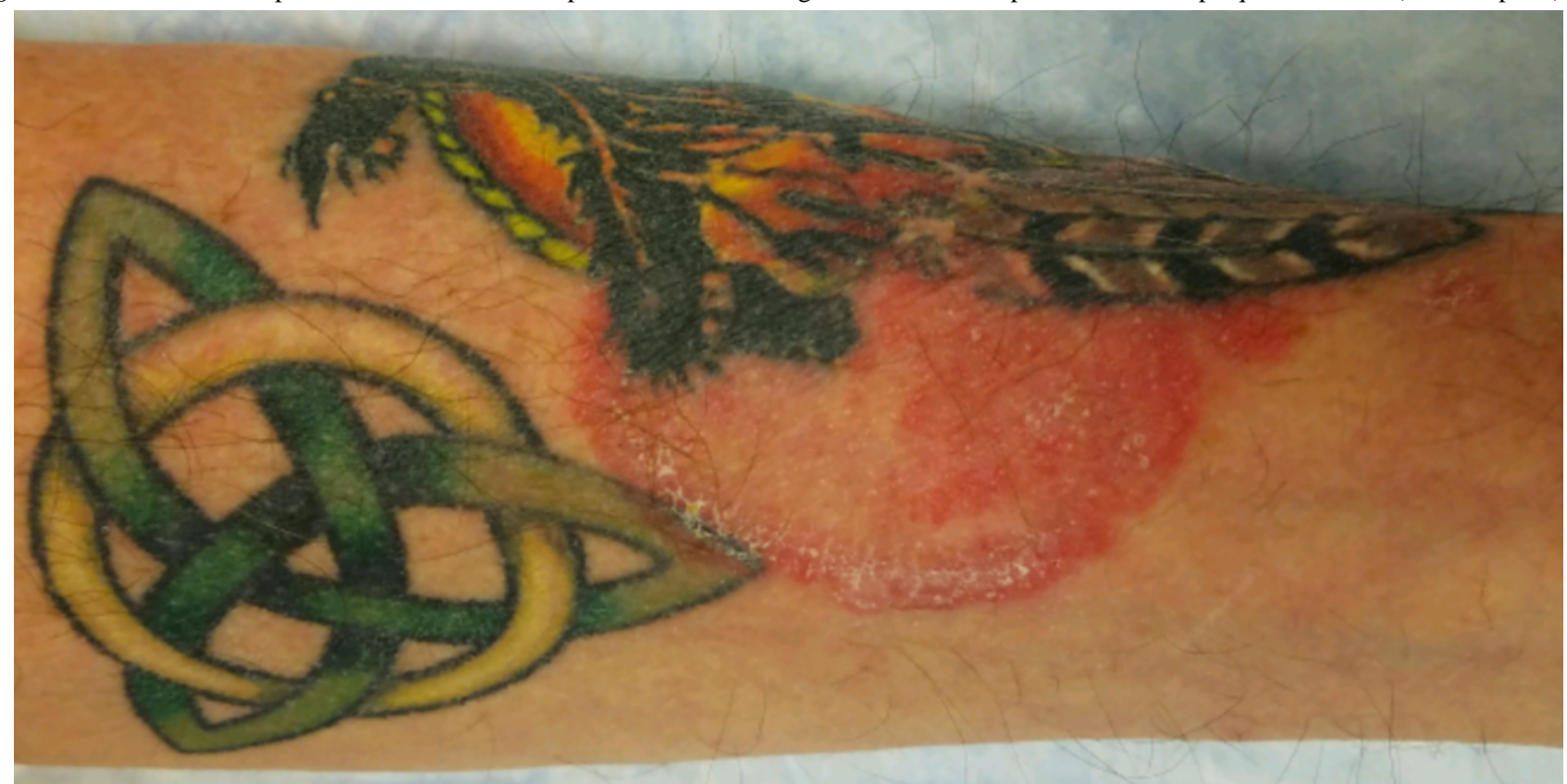

\section{Case 3}

A 26-year-old male with a 3-day history of a round pink plaque on the left cheek, within which were papules and erosions, was referred to teledermatology. At the time of his referral, the referring provider had prescribed treatment of this plaque with topical clotrimazole. The patient reported that he had worn a mask and participated in paintball and jiujitsu a few days prior to presentation and that his lesions appeared shortly afterwards. He reported that the lesion started as a pimple or vesicle, and 
then progressed into a plaque. A single submitted clinical image showed a limited view of the left cheek (Figure 6). The teledermatologist's differential diagnosis included impetigo, tinea faciei, Majocchi granuloma, and contact dermatitis. The teledermatologist advised the referring provider to obtain a superficial bacterial culture of the plaque, continue clotrimazole, and start empiric treatment with doxycycline if the patient was unable to return for the culture. The patient subsequently

Figure 6. Case 3. Limited view of the face from teledermatologist consult. reported progression of his rash and was scheduled for an in-person visit with the dermatologist 1 week later. At that time, the initial lesions had crusted over, and new lesions on his left upper medial cheek, left nasal bridge, and left nasal ala in a dermatomal distribution were noted (Figure 7). A clinical diagnosis of herpes zoster was made, the patient was prescribed oral acyclovir, and the rash subsequently resolved.

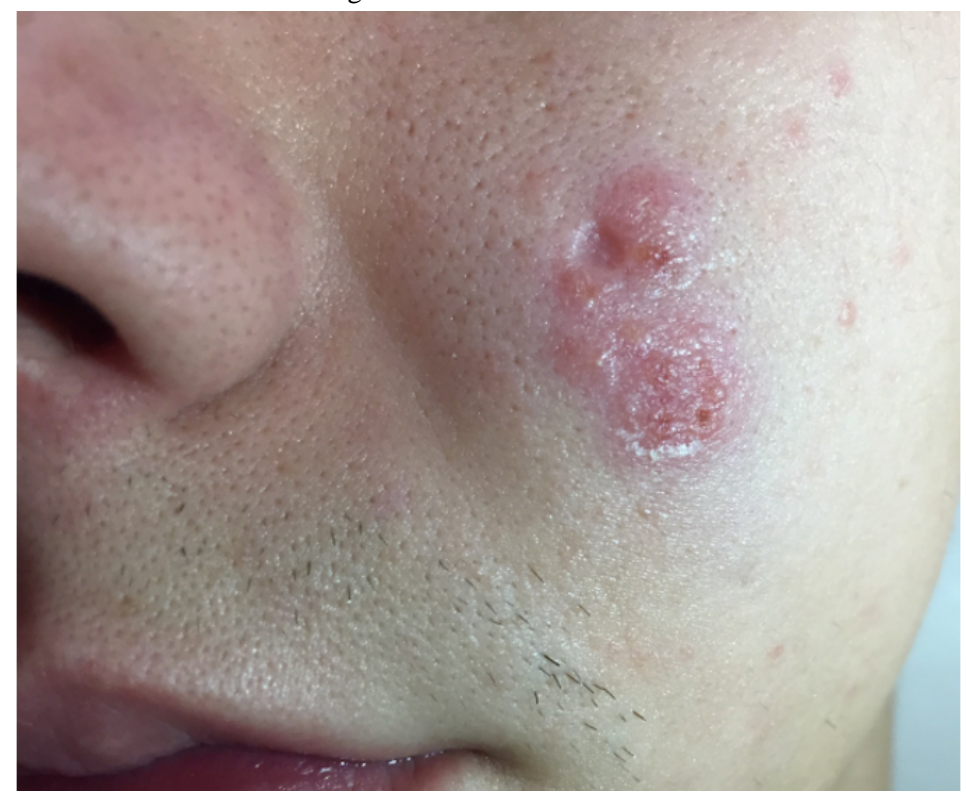

Figure 7. Case 3. Images from clinic 1 week later.

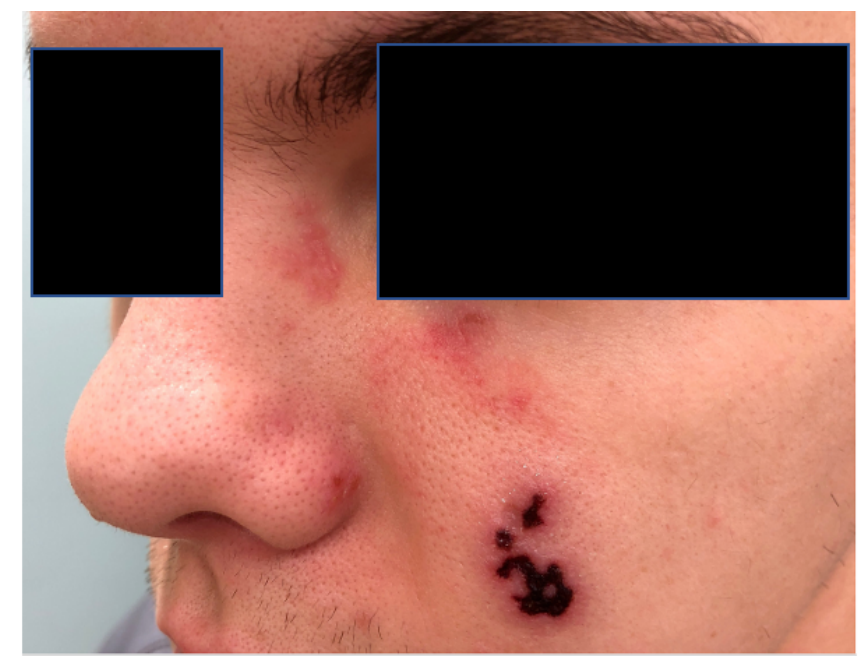

\section{Case 4}

A 63-year-old man was referred to teledermatology for evaluation of a 7-month history of an enlarging nasal lesion. The teledermatologist reviewed the image and described erythematous macules that appeared to have scale or crust on the nasal tip and ala (Figure 8). The differential diagnosis provided by the teledermatologist was dependent on textural characteristics and included actinic keratoses if the lesion was rough and excoriated papulopustular rosacea if the texture was not rough. The teledermatologist requested additional textural information. Due to the incomplete information on skin texture, the patient was referred for an in-person visit, where his exam revealed no overlying scale or roughness to suggest actinic keratosis and no features suggestive of squamous cell carcinoma. He denied a history of facial flushing or acneiform or pustular eruptions. He was clinically diagnosed with a telangiectasia, likely due to dermatoheliosis, and no further treatment was recommended. 
Figure 8. Case 4. Submitted image to teledermatology showing erythematous macules with apparent scale or crust on the nasal tip and ala.

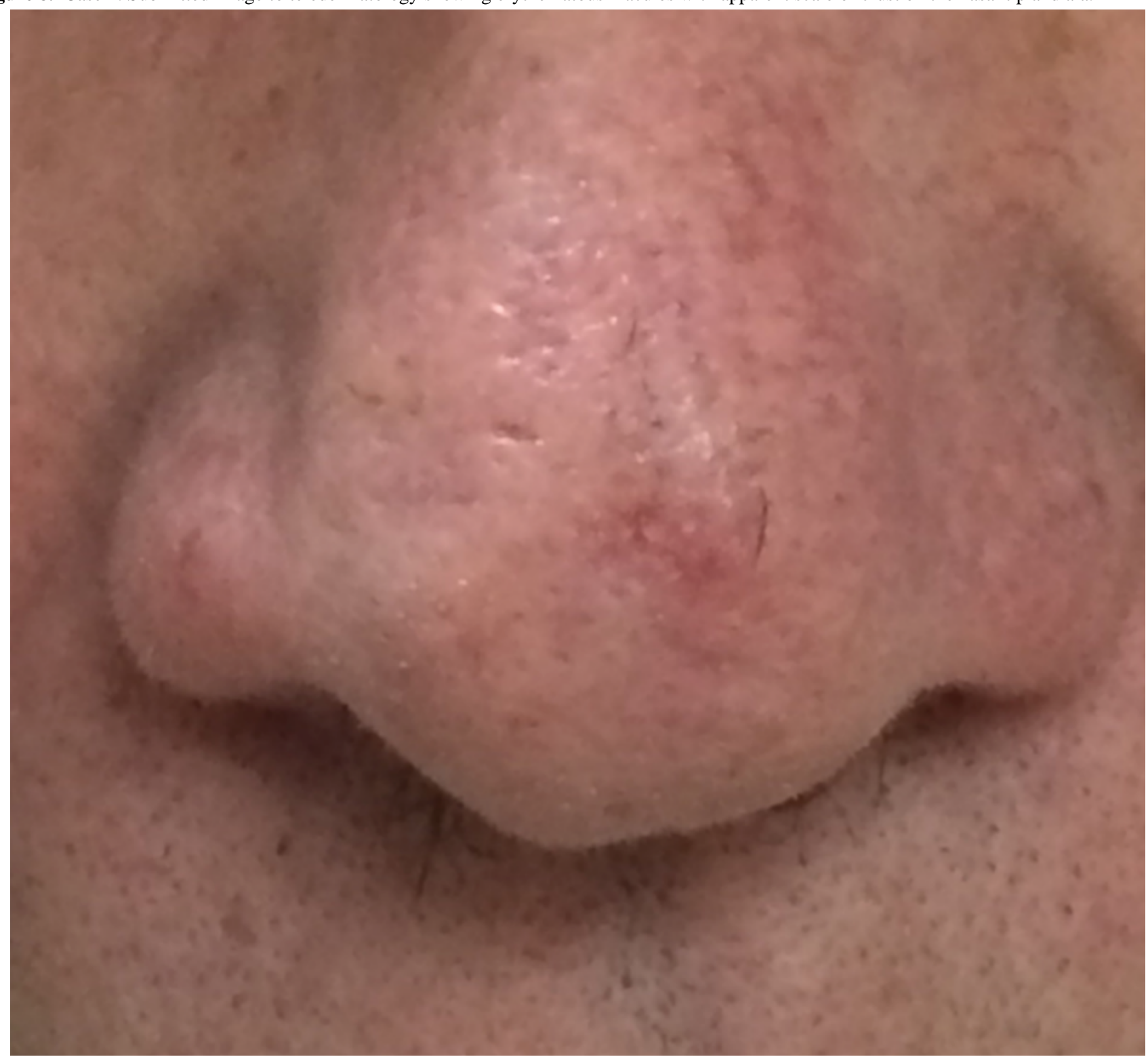

\section{Case 5}

A 69-year-old man with a 2-month history of blistering lips with skin peeling and pain unresponsive to Vaseline was referred to teledermatology. The submitted image showed a focal erosion with hemorrhagic crust and vesiculation (Figure 9), and the differential included herpes simplex virus (HSV), erythema multiforme, contact dermatitis, pemphigus vulgaris, and paraneoplastic pemphigus. The teledermatologist pointed out that the patient was not asked about history of similar eruptions, involvement of the oral mucosa, or associated symptoms including pain or burning, which would have aided the diagnosis. The consultant also recommended obtaining HSV/varicella zoster virus viral cultures and applying emollient, and the patient was scheduled for an in-office dermatology appointment. During the first in-person visit, the erosions and vesicles were resolving (Figure 10), and a bacterial culture was taken from a focal erosion which grew methicillin-resistant Staphylococcus aureus. He was treated with doxycycline and the fissure healed. The lip erosions subsequently recurred (Figure 11) and were biopsied, with pathology most consistent with a lichenoid dermatitis. He was treated with triamcinolone $0.1 \%$ cream and his symptoms resolved. 
Figure 9. Case 5. Submitted teledermatology image of focal erosion with hemorrhagic crust and vesiculation on lips.

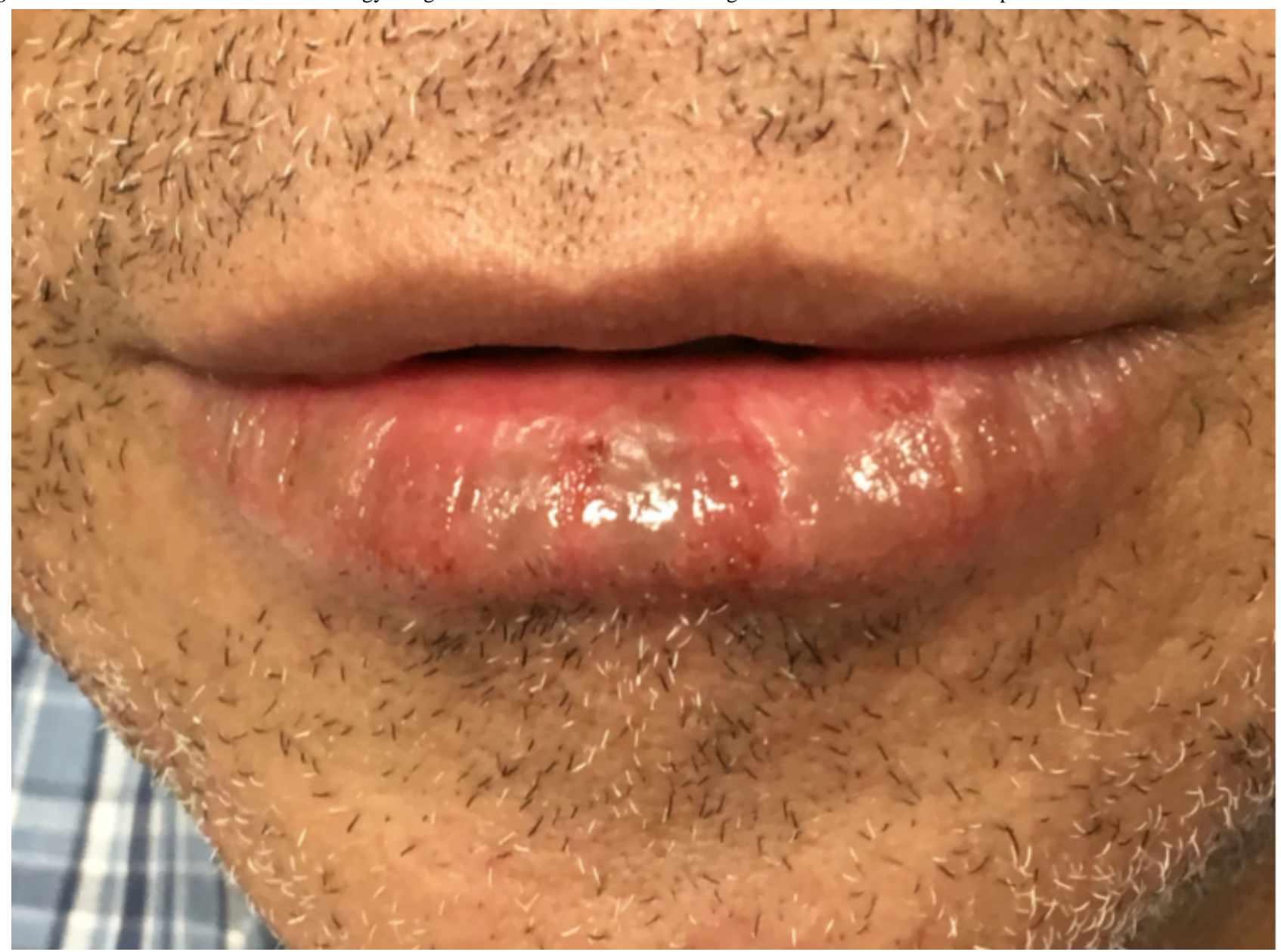

Figure 10. Case 5. Image from first in-person visit showing resolving vesicles and erosions.

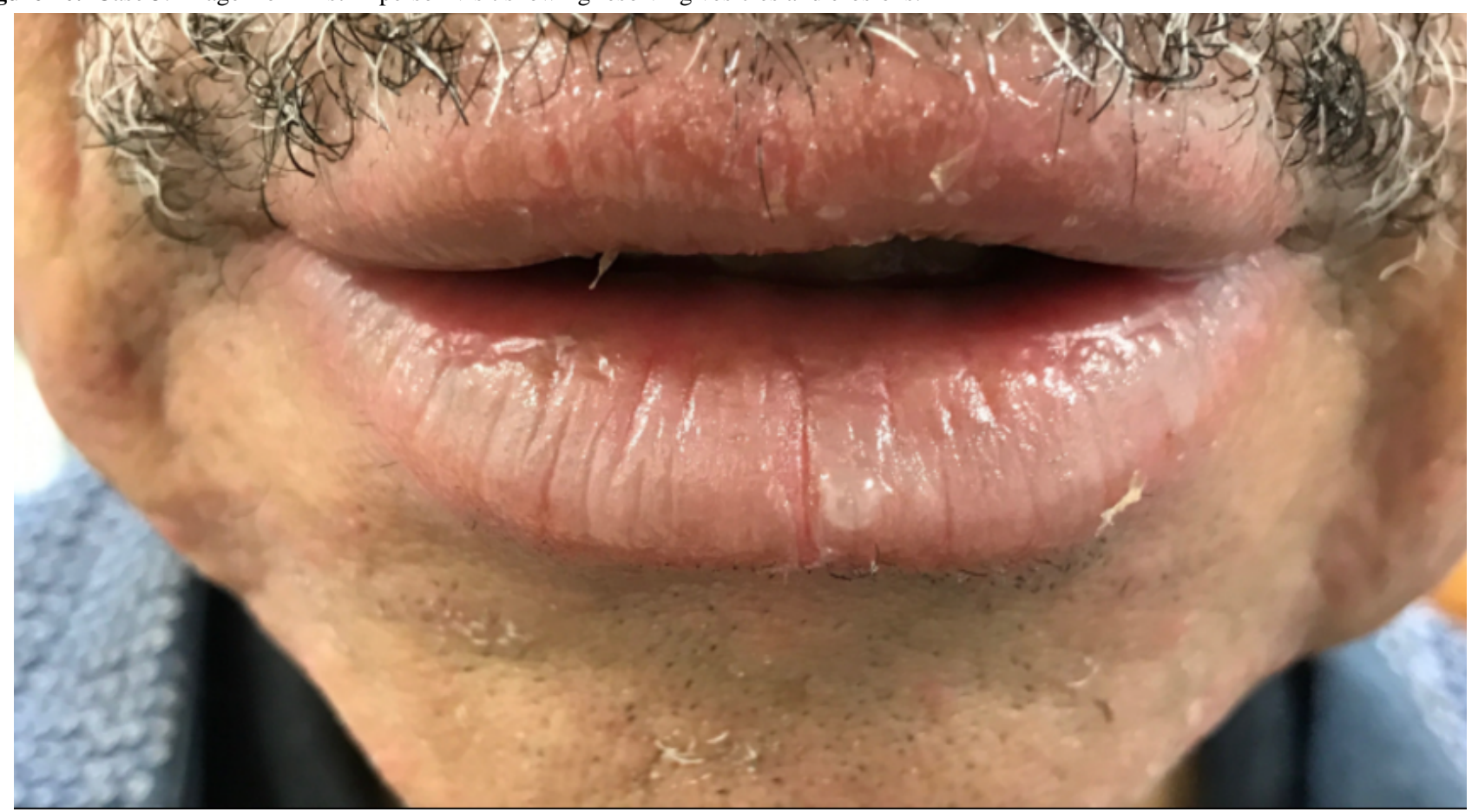


Figure 11. Case 5. Image from second in-person visit, when biopsy was taken.

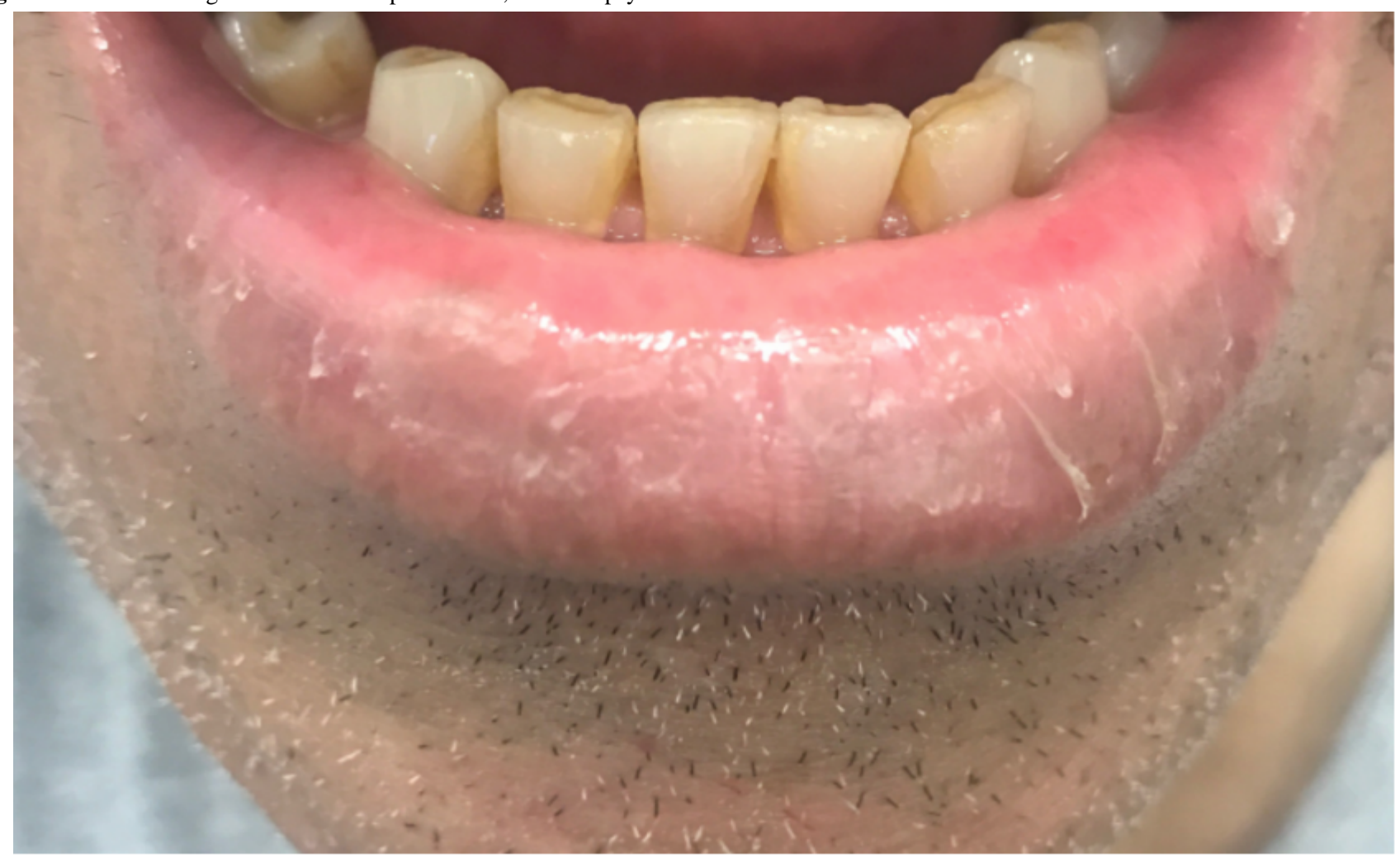

\section{Case 6}

A 41-year-old man with no known history of sexually transmitted infections was referred to teledermatology for 1 month of an unchanging nontender penile rash. He was in a monogamous relationship, and his female partner did not have a similar rash. Submitted images demonstrated a cluster of apparent deep-seated vesicles or pustules on the dorsal penile shaft (Figure 12) as well as documented 1.5-2 $\mathrm{cm}$ suprapubic lymphadenopathy. The teledermatologist noted difficulty in distinguishing between vesicles and pustules in the images and recommended obtaining a medication history as well as viral and bacterial swab culture for genital vesicles and pustules. The differential included infectious and inflammatory etiologies, including HSV, lymphogranuloma venereum, and a fixed drug eruption. The patient was scheduled for an in-person evaluation (Figure 13), during which a shave biopsy was obtained that demonstrated a foreign body giant cell reaction suggestive of a ruptured epidermal inclusion cyst. 
Figure 12. Case 6. Submitted teledermatology image suggestive of vesicles versus pustules on the dorsal penile shaft.

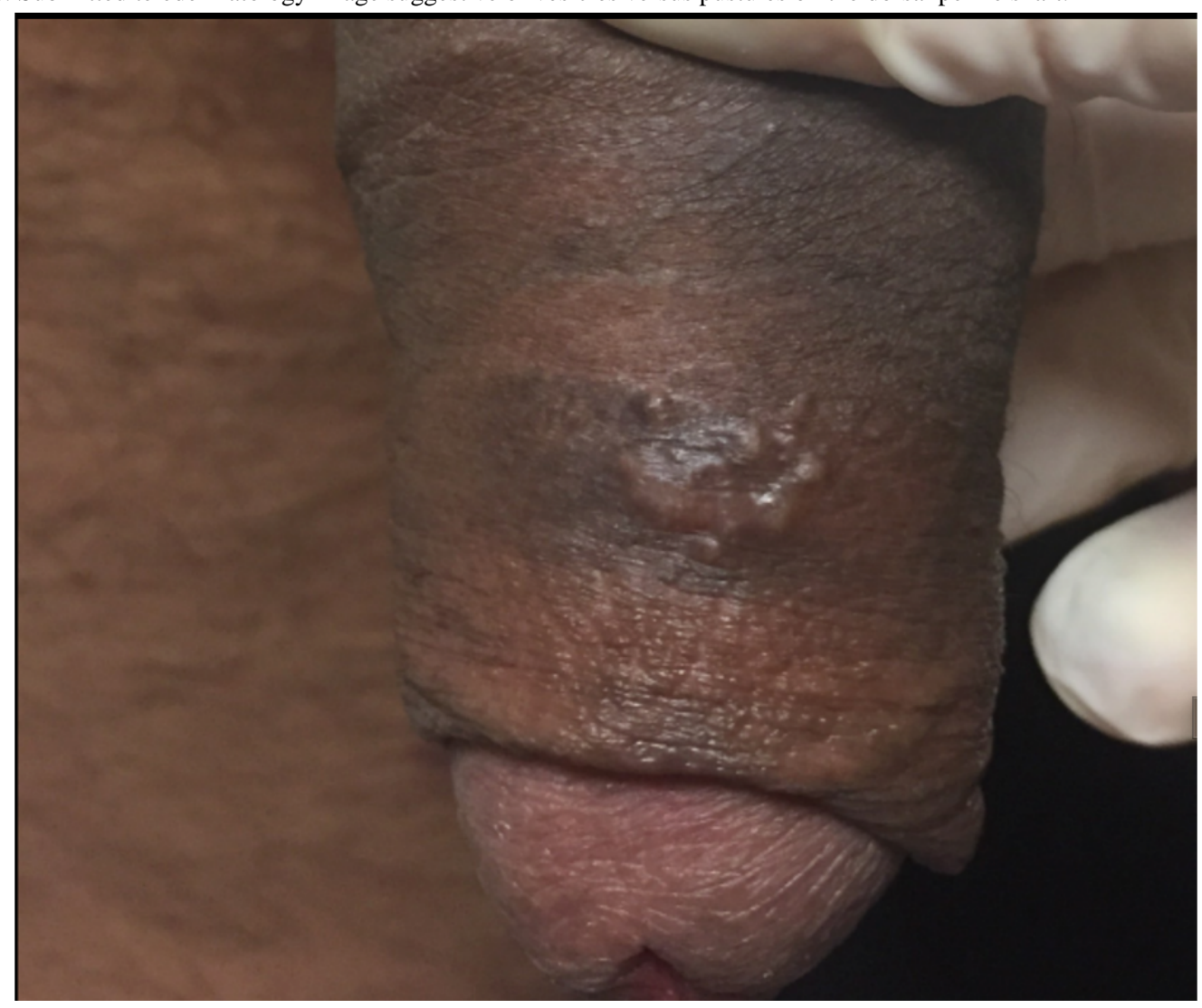

Figure 13. Case 6. Image from in-person visit.

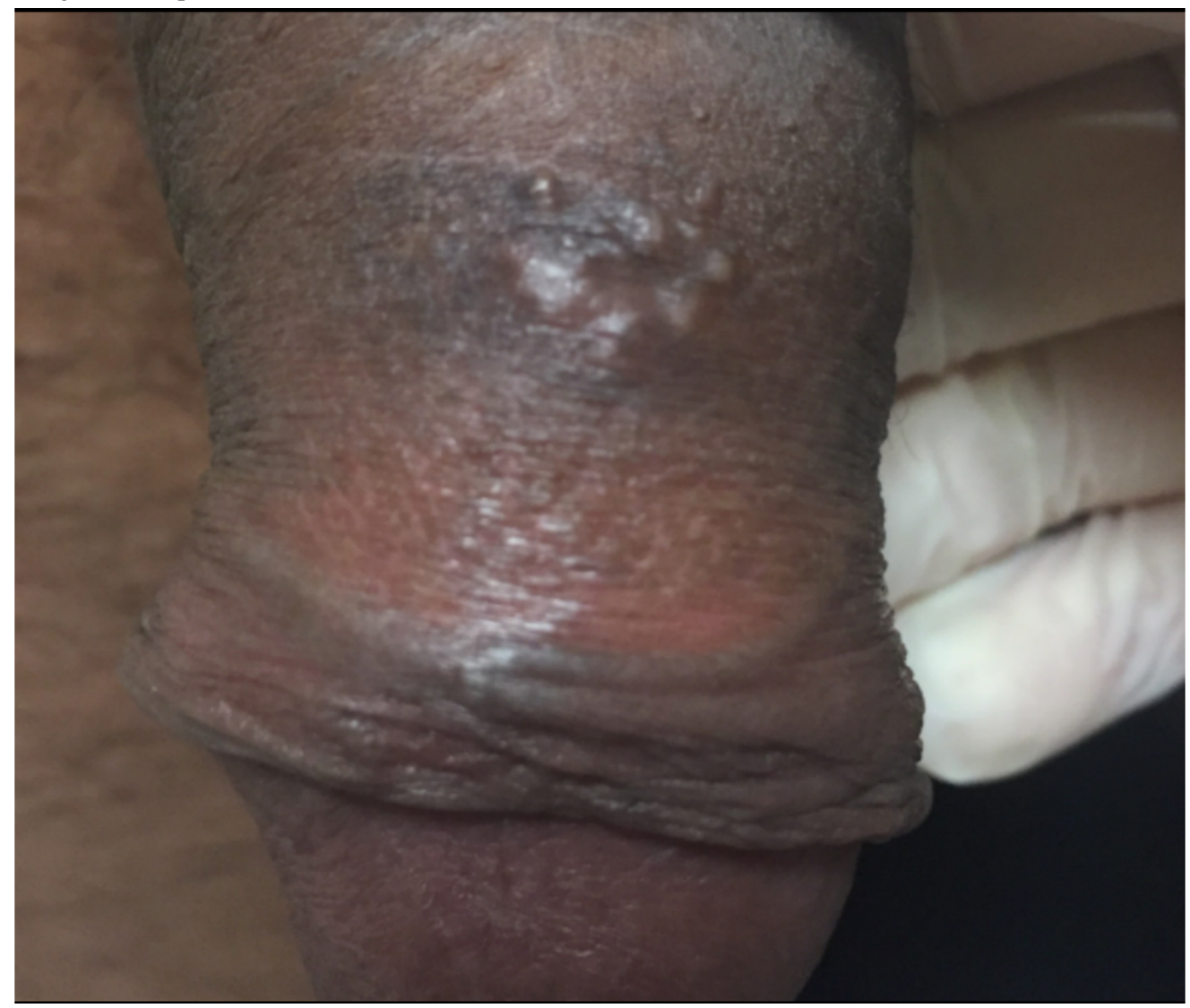




\section{Case 7}

A 66-year-old man with a 1- to 2-year history of a hyperpigmented nasal papule was referred for teledermatology consultation. The teledermatologist noted that the two dermatoscopic images provided were poorly focused (Figures 14 and 15), and no gross images were submitted. Thus, the consultant was unable to provide a differential diagnosis with

the provided clinical images, and the patient was referred for an in-person visit. During the in-office encounter, exam revealed a 5-6 mm black thin papule with a collarette of scale on the nasal bridge (Figure 16) with a differential of irritated seborrheic keratosis versus melanoma. A shave biopsy was performed of the lesion, which resulted in a diagnosis of pigmented basal cell carcinoma. The patient was referred for Mohs surgery.

Figure 14. Case 7. Submitted image to teledermatologist taken with dermoscopy.

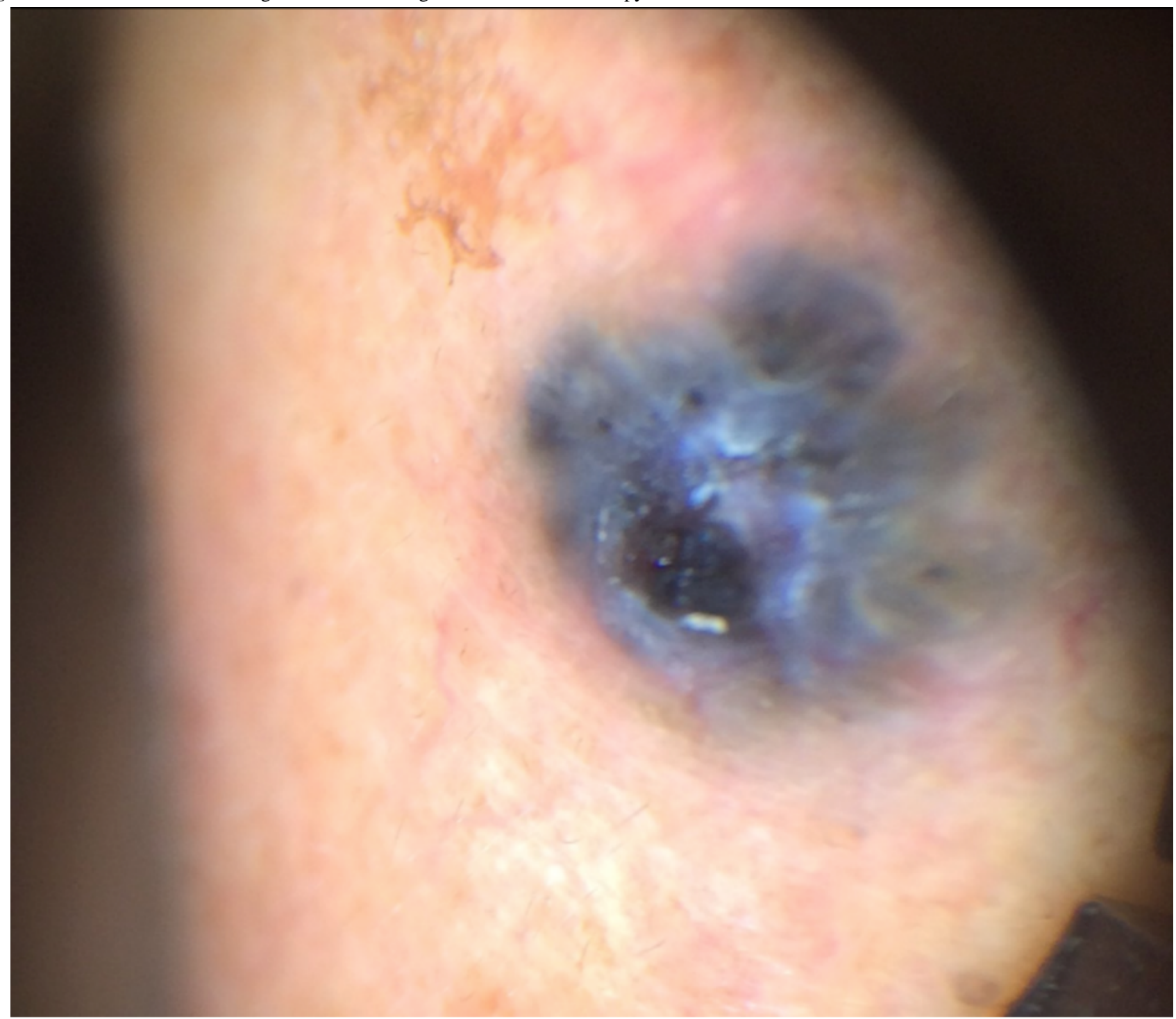


Figure 15. Case 7. Submitted image to teledermatologist taken with dermoscopy.

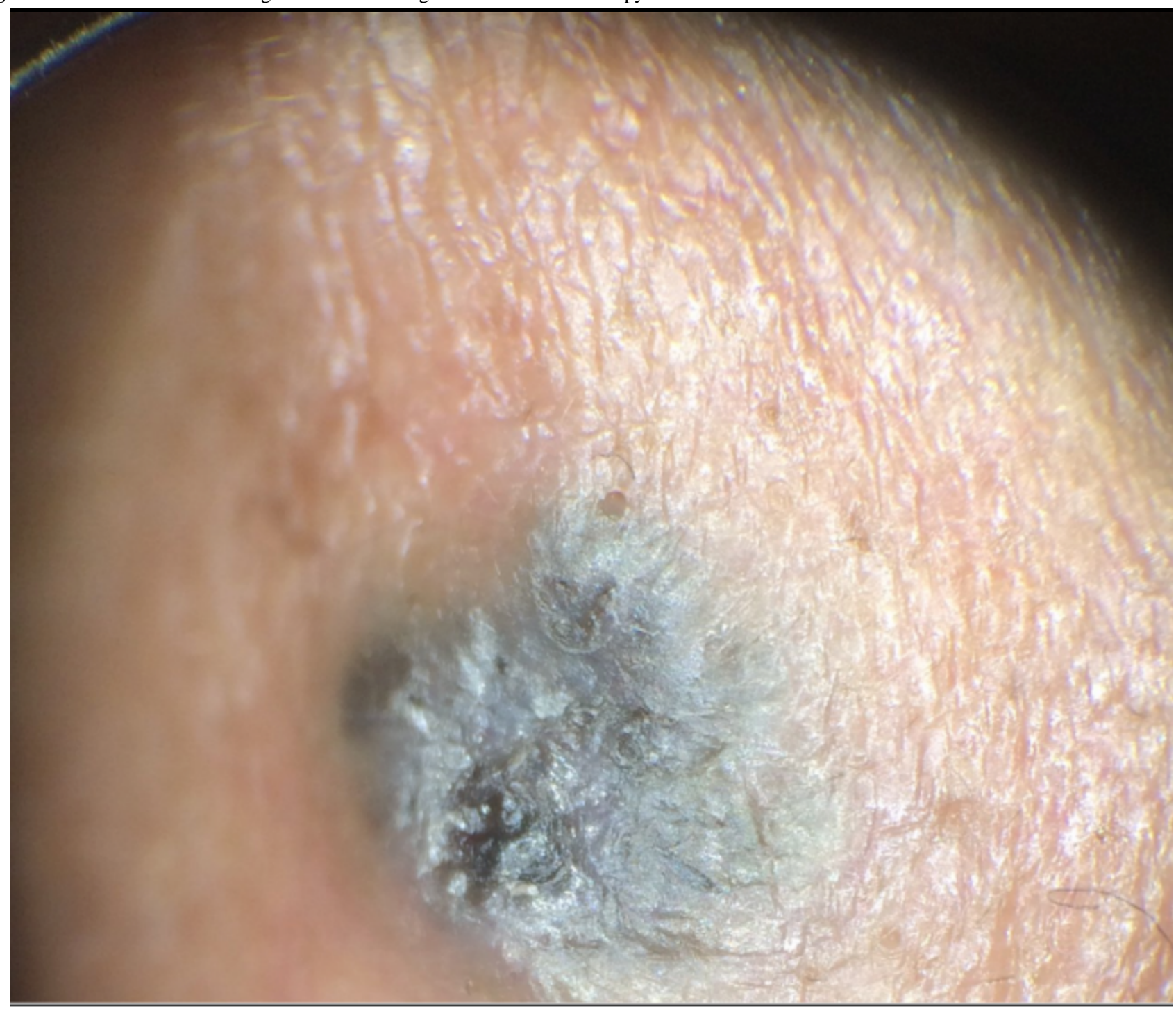


Figure 16. Case 7. In-person image showing 5-6 mm black thin papule with collarette of scale on the nasal bridge.

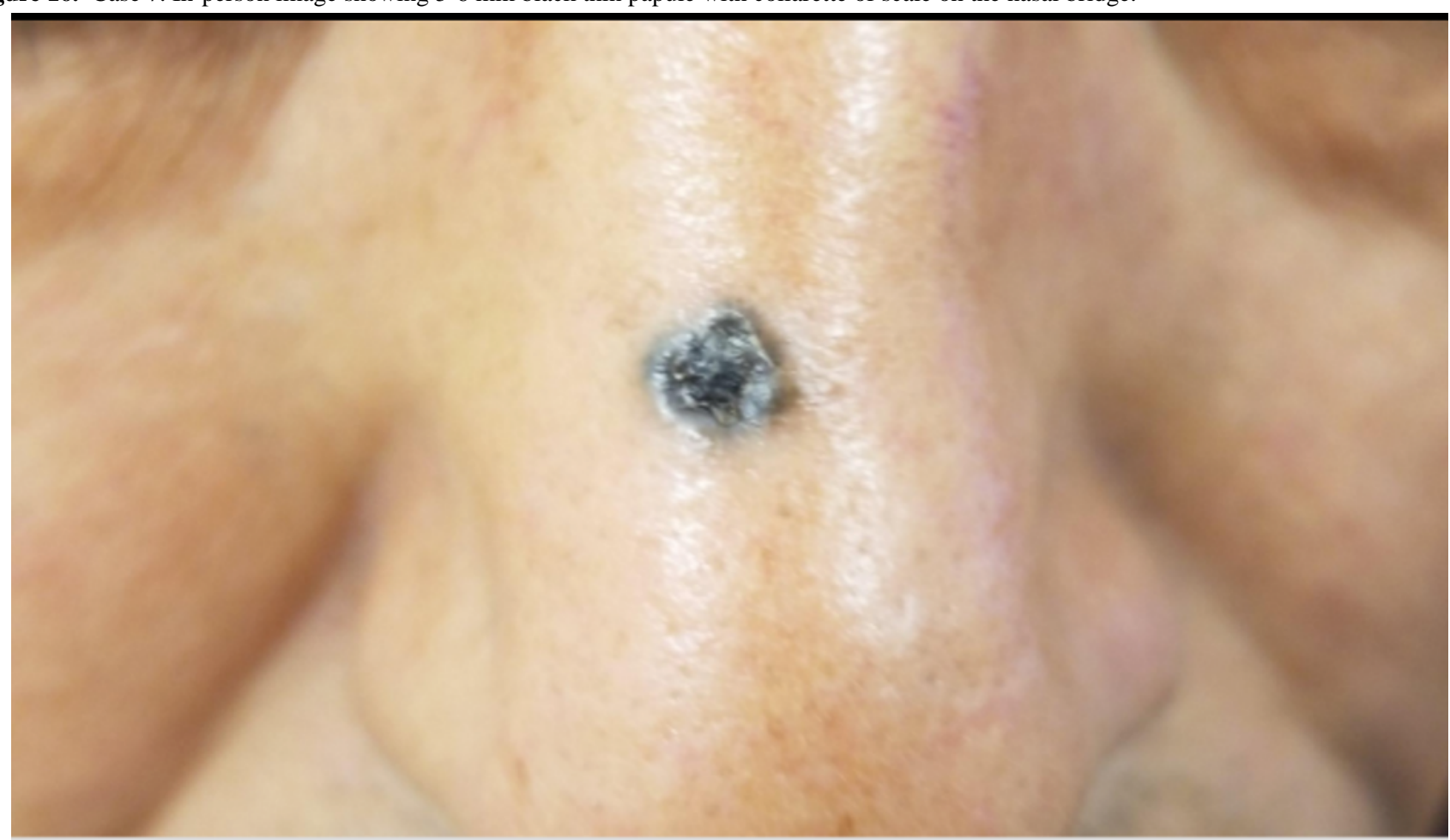

\section{Discussion}

\section{Principal Results}

From our case analysis, we identified multiple factors that likely contributed to diagnostic discordance between SAF teledermatology consultations and in-person visits in these cases. One contributing factor was poor image quality, including use of bright lighting creating shine artifact (case 1), submission of photos that showed partial views without showing the entire anatomic area involved (cases 1, 2, 3, and 7), and poorly focused images (case 7). These cases demonstrate the importance of education on appropriate image acquisition techniques. Following previously published best practices [21,22] and ongoing feedback to providers submitting photos may facilitate improved photo quality over time.

In some cases, additional clinical history or diagnostic tests provided by the referring clinician would have been helpful in narrowing the differential diagnosis. For example, diagnostic accuracy may have increased if the referring provider had performed bedside diagnostics such as superficial wound cultures, viral cultures, $\mathrm{KOH}$ preps (cases 2, 3, and 5), or dermoscopy (case 7). Use of dermoscopy has previously been shown to be a helpful tool in teledermatology programs, particularly in the evaluation of pigmented lesions [12]. Improved training of referring providers in using these diagnostic modalities may be helpful by providing clinical data to the dermatologist that leads to improved diagnostic accuracy. In addition, many cases illustrate the importance of a complete relevant medical history. For example, in case 6, a clinical history of similar vesicular eruptions, involvement of the oral mucosa, new exposures in the affected area, and associated pain or burning would have been helpful in differentiating between $\mathrm{HSV}$, erythema multiforme, contact dermatitis, or pemphigus.
Similarly, increased education for referring providers around questions relevant to certain dermatologic presentations (ie, asking about involvement of oral mucosa for bullous eruptions) would help them obtain an optimal history to aid in diagnosis.

Even with high-quality images, some morphologic characteristics may be difficult to appreciate with photos given visual limitations and inability to evaluate textural characteristics. For example, in case 4, palpation for detection of scale and induration may have helped the teledermatologist differentiate actinic damage from telangiectasias, and the teledermatologist interpreted the initial submitted image as a lesion with apparent overlying scale or crust, which was not seen in person. Case 6 also highlights that cystic, pustular, and vesicular structures can sometimes be difficult to distinguish from photos alone, depending on the angle and lighting of the photo taken. These cases highlight inherent diagnostic limitations of teledermatology services.

Finally, some factors such as atypical presentations and evolution of skin lesions over time were not specific to teledermatology and may have occurred in an initial in-person visit as well. For example, multiple cases remained diagnostically challenging even when patients were seen in person due to atypical presentations (cases 1, 5, and 6). Additionally, cases 2 and 3 highlight how morphology and distribution can evolve over time, leading to changes in suspected diagnosis. Teledermatology may have the highest utility for cases with typical presentations as unusual presentations may be difficult for teledermatologists to manage confidently without in-person evaluation and possible skin biopsy. Recognition of these limitations may also help with appropriate selection of patients more likely to benefit from an in-person encounter rather than a teledermatology visit. Even when patients can be managed with teledermatology, it is 
important for patients and providers to maintain follow-up to ensure appropriate response to management and ongoing support if the patient's condition or morphology changes from the time of original teledermatology consultation.

Our study has important implications given that the use of asynchronous and other types of virtual care continues to rise $[9,10]$, as incorrect diagnosis via teledermatology or lack of a timely referral for an in-person visit may have potential negative consequences for patients. For example, case 2 highlights how a teledermatologist's incorrect diagnosis and prescription of betamethasone for tinea corporis may have contributed to the progression of the rash, although the correct diagnosis also may not have been made at an initial in-person visit given its atypical presentation. In case 7 , it was essential that a timely referral was made given the indeterminate images, which allowed the patient to receive a biopsy resulting in a diagnosis of pigmented basal cell carcinoma.

In order to improve the quality of SAF consultations and decrease rates of diagnostic discordance, we advocate for use of a standardized guide to help improve the quality of SAF teledermatology consults, including image quality and appropriate workup. In addition to guidelines already outlined by the American Telemedicine Association [21,22], our study highlights the need for guidelines for proper lighting, examples of dermoscopy images, relevant questions to ask in the patient history for certain morphologic presentations, and certain suggested diagnostic tests to perform before submitting a consult.

In addition, the educational value of SAF consults should continue to be emphasized to both referring and consulting providers in order to help improve the quality of consults and ensure the highest level of diagnostic accuracy. Referring providers' ability to obtain an optimal history and diagnostic testing will also likely improve with increased use of SAF teledermatology and iterative dialogue between providers about patients' medical management. For example, previous studies have highlighted the educational potential of SAF teledermatology systems on improving referring primary care provider knowledge of dermatologic care [23]. Teledermatologists should also be encouraged to engage in education with referring providers to ensure this ongoing learning process.

The strengths of our study include its in-depth analysis of specific cases and side-by-side comparison of teledermatology and in-person consults for the same patients. While several studies have been published on overall rates of diagnostic discordance, which have been estimated at around 39\%-67\% $[12-17,19]$, none to our knowledge have presented a case-by-case analysis that illustrates and compares the teledermatology and in-person visits for the same patients.

\section{Limitations}

Some of the limitations of our study include that our sample size limits our ability to generalize across all cases of diagnostic concordance, although we intend for this to be a more in-depth study of fewer cases. In addition, only one teledermatologist reviewed each image submitted by the referring provider, which may introduce the possibility that diagnostic uncertainty may have been due to the individual teledermatologist's level of comfort with the diagnosis rather than the inherent limitations of teledermatology. The teledermatologist was also different than the in-person dermatologist in all but the second case, and thus some of the differences in experience and comfort level between the teledermatologists and in-person dermatologists may have contributed to the discordant diagnoses.

\section{Conclusions}

Collectively, these cases highlight factors that can contribute to diagnostic discordance between teledermatologist and in-person dermatologist and the importance of ensuring that teledermatology services are supported by readily available in-person visits when appropriate to achieve the correct diagnosis in these cases. We also highlight the importance of ongoing education of referring providers to ensure optimal history and diagnostic workup and improve quality of consultations and the development of standardized guidelines for submitting referrals.

Teledermatology can provide substantial benefits to patients, and recognition of its limitations and mitigation of the factors identified in these cases provide opportunities to improve the quality and diagnostic accuracy of SAF teledermatology services.

\section{Conflicts of Interest}

None declared.

\section{References}

1. Snoswell C, Finnane A, Janda M, Soyer HP, Whitty JA. Cost-effectiveness of Store-and-Forward Teledermatology: A Systematic Review. JAMA Dermatol 2016 Jun 01;152(6):702-708. [doi: 10.1001/jamadermatol.2016.0525] [Medline: 27074289]

2. Rajda J, Seraly MP, Fernandes J, Niejadlik K, Wei H, Fox K, et al. Impact of Direct to Consumer Store-and-Forward Teledermatology on Access to Care, Satisfaction, Utilization, and Costs in a Commercial Health Plan Population. Telemed J E Health 2018 Feb;24(2):166-169. [doi: 10.1089/tmj.2017.0078] [Medline: 28742431]

3. Datta SK, Warshaw EM, Edison KE, Kapur K, Thottapurathu L, Moritz TE, et al. Cost and Utility Analysis of a Store-and-Forward Teledermatology Referral System: A Randomized Clinical Trial. JAMA Dermatol 2015 Dec 01;151(12):1323-1329. [doi: 10.1001/jamadermatol.2015.2362] [Medline: 26375589] 
4. Lasierra N, Alesanco A, Gilaberte Y, Magallón R, García J. Lessons learned after a three-year store and forward teledermatology experience using internet: Strengths and limitations. Int J Med Inform 2012 May;81(5):332-343. [doi: 10.1016/j.ijmedinf.2012.02.008] [Medline: 22425394]

5. Chuchu N. Teledermatology for diagnosing skin cancer in adults. Cochrane Database Syst Rev 2018;12. [doi: 10.1002/14651858.cd013193] [Medline: $\underline{\text { 30521686] }}$

6. Finnane A, Dallest K, Janda M, Soyer HP. Teledermatology for the Diagnosis and Management of Skin Cancer: A Systematic Review. JAMA Dermatol 2017 Mar 01;153(3):319-327. [doi: 10.1001/jamadermatol.2016.4361] [Medline: 27926766]

7. Naka F, Lu J, Porto A, Villagra J, Wu ZH, Anderson D. Impact of dermatology eConsults on access to care and skin cancer screening in underserved populations: A model for teledermatology services in community health centers. J Am Acad Dermatol 2018 Feb;78(2):293-302. [doi: 10.1016/j.jaad.2017.09.017] [Medline: 29061478]

8. G Bianchi M, Santos A, Cordioli E. Benefits of Teledermatology for Geriatric Patients: Population-Based Cross-Sectional Study. J Med Internet Res 2020 Apr 21;22(4):e16700 [FREE Full text] [doi: 10.2196/16700] [Medline: 32314966]

9. Ramaswamy A, Yu M, Drangsholt S, Ng E, Culligan PJ, Schlegel PN, et al. Patient Satisfaction With Telemedicine During the COVID-19 Pandemic: Retrospective Cohort Study. J Med Internet Res 2020 Sep 09;22(9):e20786 [FREE Full text] [doi: $10.2196 / 20786]$ [Medline: 32810841$]$

10. Su MY, Das S. Expansion of asynchronous teledermatology during the COVID-19 pandemic. J Am Acad Dermatol 2020 Dec;83(6):e471-e472 [FREE Full text] [doi: 10.1016/j.jaad.2020.08.054] [Medline: 32822793]

11. Brinker TJ, Hekler A, von Kalle C, Schadendorf D, Esser S, Berking C, et al. Teledermatology: Comparison of Store-and-Forward Versus Live Interactive Video Conferencing. J Med Internet Res 2018 Oct 24;20(10):e11871 [FREE Full text] [doi: 10.2196/11871] [Medline: 30355564 ]

12. Piccolo D, Smolle J, Argenziano G, Wolf IH, Braun R, Cerroni L, et al. Teledermoscopy--results of a multicentre study on 43 pigmented skin lesions. J Telemed Telecare 2000;6(3):132-137. [doi: 10.1258/1357633001935202] [Medline: 10912329]

13. Warshaw EM, Hillman YJ, Greer NL, Hagel EM, MacDonald R, Rutks IR, et al. Teledermatology for diagnosis and management of skin conditions: a systematic review. J Am Acad Dermatol 2011 Apr;64(4):759-772. [doi: 10.1016/j.jaad.2010.08.026] [Medline: 21036419]

14. Warshaw EM, Gravely AA, Nelson DB. Reliability of store and forward teledermatology for skin neoplasms. J Am Acad Dermatol 2015 Mar;72(3):426-435. [doi: 10.1016/j.jaad.2014.11.001] [Medline: 25599624]

15. Warshaw EM, Gravely AA, Nelson DB. Accuracy of teledermatology/teledermoscopy and clinic-based dermatology for specific categories of skin neoplasms. J Am Acad Dermatol 2010 Aug;63(2):348-352. [doi: 10.1016/j.jaad.2009.10.037] [Medline: 20633809]

16. Piccolo D, Smolle J, Wolf IH, Peris K, Hofmann-Wellenhof R, Dell'Eva G, et al. Face-to-face diagnosis vs telediagnosis of pigmented skin tumors: a teledermoscopic study. Arch Dermatol 1999 Dec;135(12):1467-1471. [doi: 10.1001/archderm.135.12.1467] [Medline: 10606051]

17. Landow SM, Mateus A, Korgavkar K, Nightingale D, Weinstock MA. Teledermatology: key factors associated with reducing face-to-face dermatology visits. J Am Acad Dermatol 2014 Sep;71(3):570-576. [doi: 10.1016/j.jaad.2014.02.021] [Medline: 24704089]

18. Dobry A, Begaj T, Mengistu K, Sinha S, Droms R, Dunlap R, et al. Implementation and Impact of a Store-and-Forward Teledermatology Platform in an Urban Academic Safety-Net Health Care System. Telemed J E Health 2020 Jun 09. [doi: 10.1089/tmj.2020.0069] [Medline: 32522105]

19. Nelson CA, Takeshita J, Wanat KA, Bream KDW, Holmes JH, Koenig HC, et al. Impact of store-and-forward (SAF) teledermatology on outpatient dermatologic care: A prospective study in an underserved urban primary care setting. $\mathrm{J}$ Am Acad Dermatol 2016 Mar;74(3):484-90.e1. [doi: 10.1016/j.jaad.2015.09.058] [Medline: 26679528]

20. Barbieri JS, Nelson CA, James WD, Margolis DJ, Littman-Quinn R, Kovarik CL, et al. The reliability of teledermatology to triage inpatient dermatology consultations. JAMA Dermatol 2014 Apr;150(4):419-424. [doi: 10.1001/jamadermatol.2013.9517] [Medline: 24522374]

21. McKoy K, Norton S, Lappan C. Quick Guide to Store-Forward Teledermatology for Referring Providers.: ATA Teledermatology SIG; 2012. URL: http://teledermatology-society.org/wp-content/uploads/2013/08/ quick-guide-to-store-forward-and-live-interactive-teledermatology-for-referring-providers.pdf [accessed 2021-01-29]

22. McKoy K, Antoniotti NM, Armstrong A, Bashshur R, Bernard J, Bernstein D, et al. Practice Guidelines for Teledermatology. Telemed J E Health 2016 Dec;22(12):981-990. [doi: 10.1089/tmj.2016.0137] [Medline: 27690203]

23. Mohan GC, Molina GE, Stavert R. Store and forward teledermatology improves dermatology knowledge among referring primary care providers: A survey-based cohort study. J Am Acad Dermatol 2018 Nov;79(5):960-961. [doi:

10.1016/j.jaad.2018.05.006] [Medline: 29753059]

\section{Abbreviations}

HSV: herpes simplex virus

KOH prep: potassium hydroxide preparation

SAF: store-and-forward 


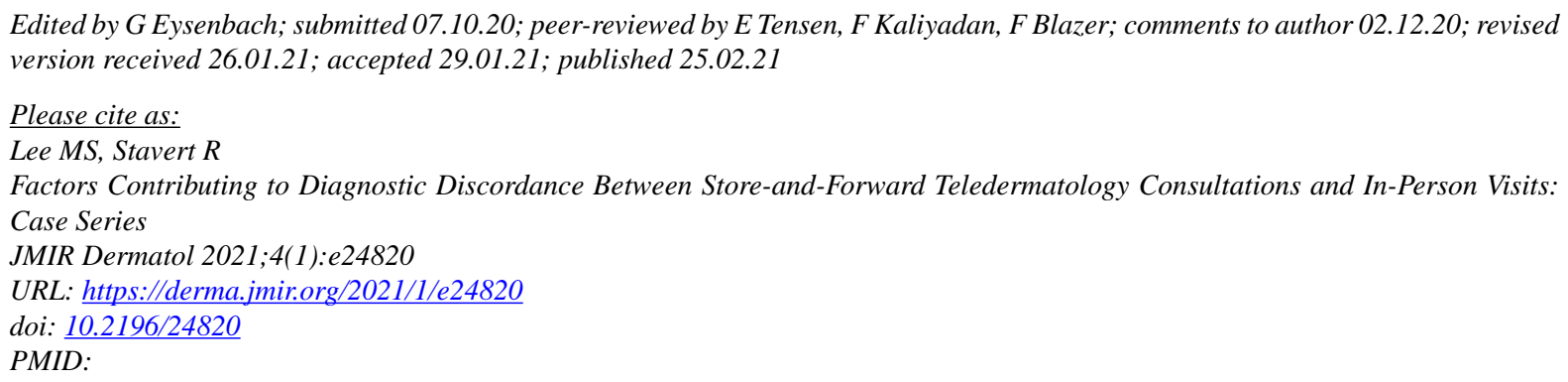

CMichelle S Lee, Robert Stavert. Originally published in JMIR Dermatology (http://derma.jmir.org), 25.02.2021. This is an open-access article distributed under the terms of the Creative Commons Attribution License (https://creativecommons.org/licenses/by/4.0/), which permits unrestricted use, distribution, and reproduction in any medium, provided the original work, first published in JMIR Dermatology Research, is properly cited. The complete bibliographic information, a link to the original publication on http://derma.jmir.org, as well as this copyright and license information must be included. 